Journal of Molecular Structure, 43 (1978) 245-249

o Elsevier Scientific Publishing Company, Amsterdam - Printed in The Netherlands

\title{
STRUCTURES OF HEXACOORDINATE COMPOUNDS OF MAIN-GROUP ELEMENTS
}

Part III. An electron diffraction study of $\mathbf{S F}_{6}$

L. S. BARTELL and S. K. DOUN

Department of Chemistry, University of Michigan, Ann Arbor, Michigan 48109 (U.S.A.)

(Received 8 August 1977)

\begin{abstract}
Gas-phase sulphur hexafluoride is a regular octahedron with an S-F bond length $\left(r_{\mathrm{g}}\right)$ of $1.561(2) \AA$ and mean amplitudes of vibration of $0.044(1) \AA$ for $S-F, 0.056(6) \AA$ for $\mathrm{F}-\mathrm{F}_{\text {trans, }}$ and $0.061(2) \&$ for $\mathrm{F}-\mathrm{F}_{c i s}$. Uncertainties correspond to $3 \sigma$.
\end{abstract}

\section{INTRODUCTION}

In the course of an investigation of the structure of $\mathrm{SF}_{5} \mathrm{Cl}$ [1], it was found that only incomplete structural information exists for $\mathrm{SF}_{6}$, the most natural reference compound for sulfur(VI)-fluorine bond lengths and a molecule under intense investigation in research on laser-induced processes [2]. Spectroscopic analyses have confirmed that the molecule possesses $O_{\mathrm{b}}$ symmetry [3] but the published diffraction studies are uncertain by about $0.02 \AA$ [4-6]. It seemed worthwhile to test predictions of the VSEPR [7] theory concerning the $\mathrm{S}-\mathrm{F}$ bond lengths in $\mathrm{SF}_{5} \mathrm{Cl}$ versus the length in $\mathrm{SF}_{6}$. Therefore, we undertook a study of $\mathrm{SF}_{6}$ by vapor-phase electron diffraction.

\section{EXPERIMENTAL}

The sample of $\mathrm{SF}_{6}$ with a stated purity of $99.99 \%$ was purchased from M. G. Scientific Co. IR spectra and vapor phase chromatograms revealed no contaminants. Mass spectrographic analyses indicated the presence of only minor concentrations of impurities. Electron diffraction patterns of a solid sample maintained at $-106^{\circ} \mathrm{C}$ were recorded on $4 \times 5$ in. Kodak Electron Image plates. Experimental conditions (see Table 1)* and analyses of data closely resemble those reported for $\mathrm{SF}_{5} \mathrm{Cl}$ [1]. $O_{\mathrm{h}}$ symmetry was assumed in least squares refinements and asymmetry constants, $a$, were taken as $1.8 \AA^{-1}$ for all internuclear distances. The shrinkage values of

*Tabulated levelled intensities $I_{0}(s)$ and background functions $I_{\mathrm{B}}(s)$ for $21-, 11-$, and $7-\mathrm{cm}$ distances are available as Sup. Pub. No. SUP 26082 (10 pages) from BLLD. 
TABLE 1

\section{Experimental conditions}

Nozzle to plate, distance, $\mathrm{cm}$

Diameter of Pt nozzle, $\mathrm{mm}$

Nozzle to beam distance, $\mathrm{mm}$

Sample reservoir temperature, ${ }^{\circ} \mathrm{C}$

Estimated sample pressure, torr

Sector used (radius, $\mathrm{mm}$ )

Exposure time, seconds

Number of plates used

Accelerating voltage, $\mathrm{kV}$

\begin{tabular}{ccc}
21.091 & 11.122 & 6.560 \\
0.25 & 0.25 & 0.25 \\
0.45 & 0.45 & 0.45 \\
-106.0 & -106.0 & -106.0 \\
25.0 & 25.0 & 25.0 \\
$r^{3}(48)$ & $r^{3}(48)$ & $r^{3}(48)$ \\
4.0 & 7.0 & 20.0 \\
5.0 & 5.0 & 5.0 \\
40.0 & 40.0 & 40.0 \\
\hline
\end{tabular}

$0.00262 \AA$ for $S-F$ and $0.00063 \AA$ for $F \cdot \cdots$ F (cis) calculated by Brunvoll [8] were adopted in all refinements.

\section{RESULTS}

The experimental and final calculated molecular intensity curves are shown in Fig. 1, and the radial distribution function in Fig. 2. Derived

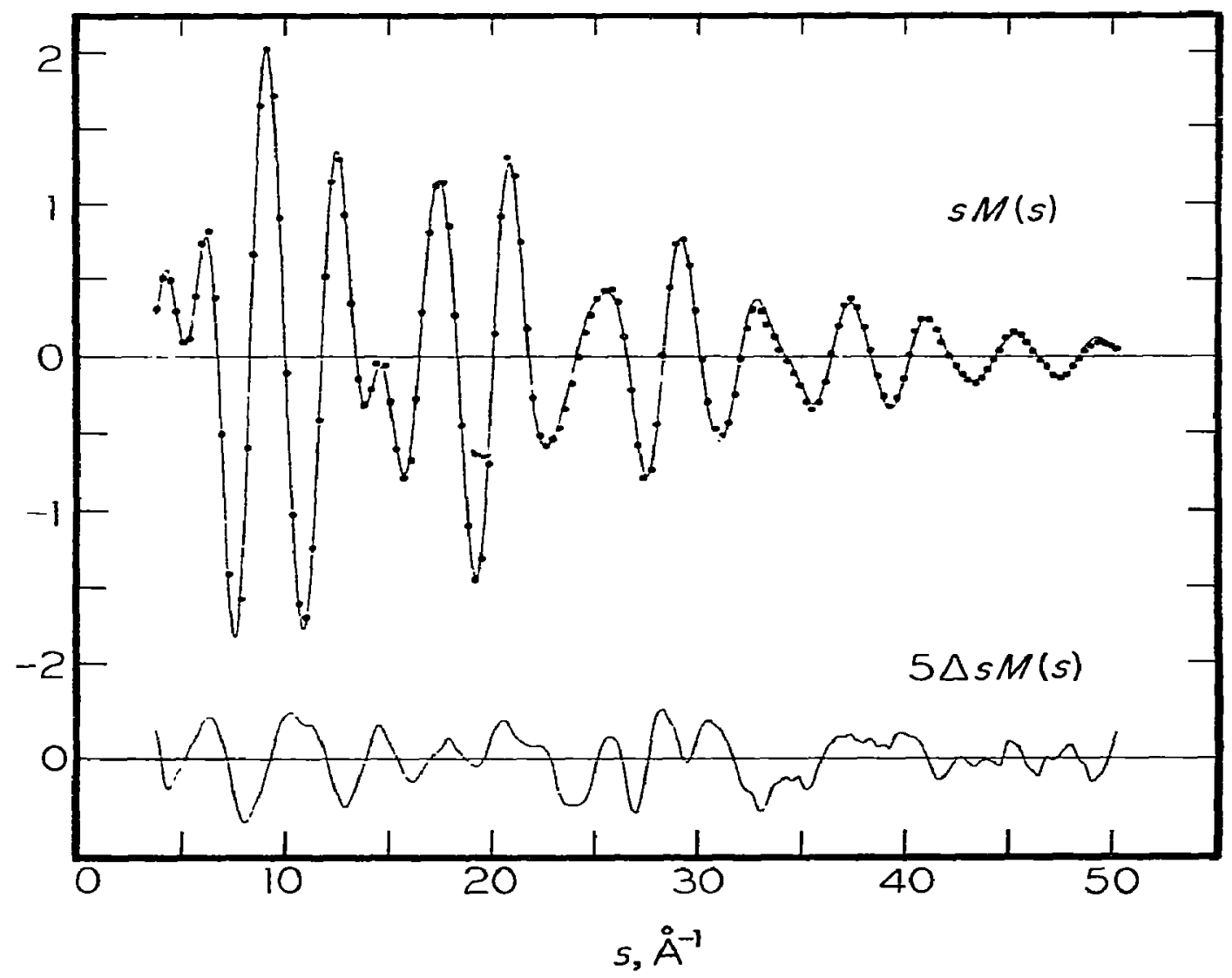

Fig. 1. Experimental (dots) and calculated (smooth curve) molecular intensity functions for $\mathrm{SF}_{\mathrm{s}} ; \Delta s M(s)=s M(s)_{\text {expt }}-s M(s)_{\text {calc }}$. 


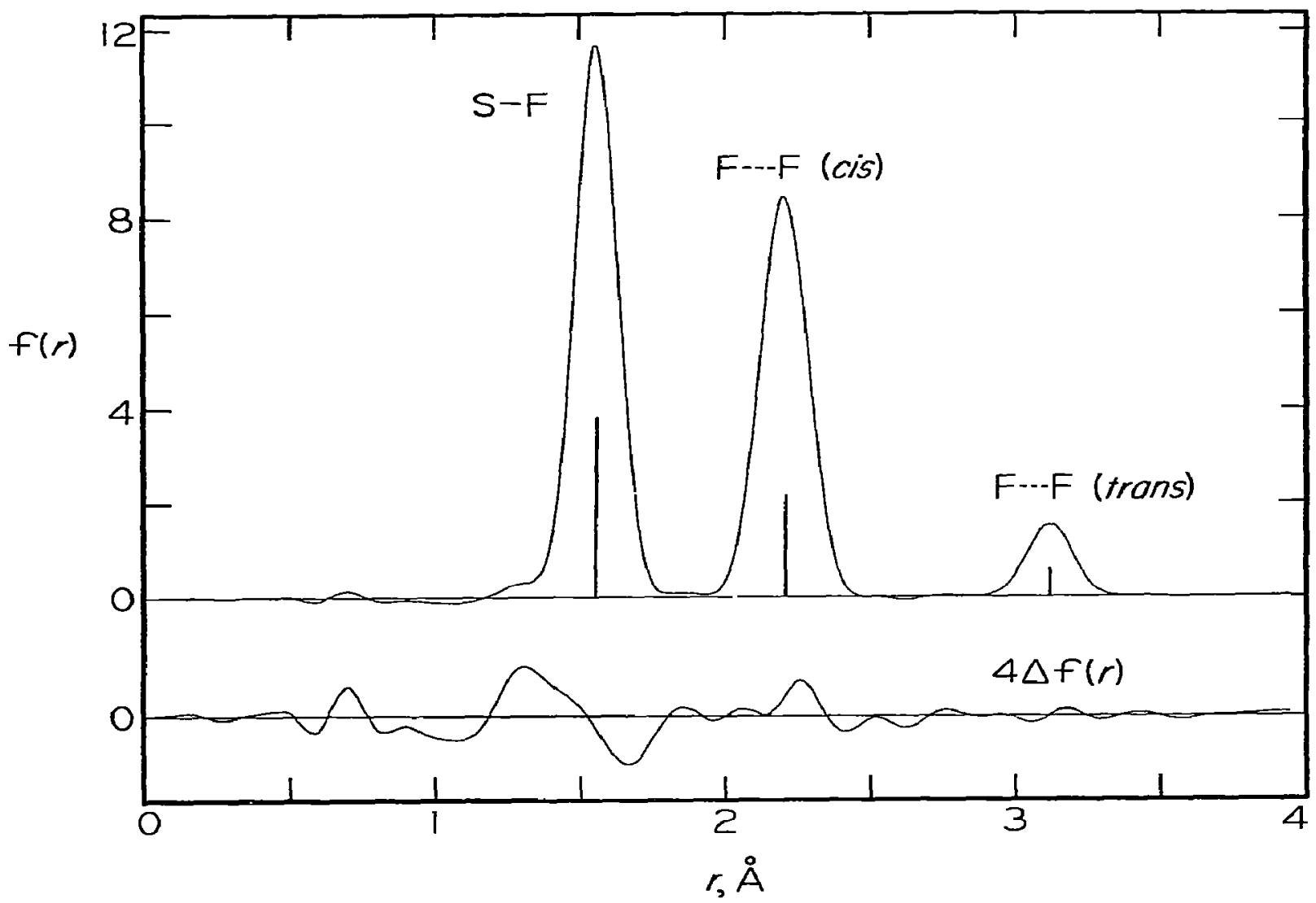

Fig. 2. Experimental radial distribution function for $S F_{6} ; \Delta f(r)=f(v)_{\text {expt }}-f(r)_{\text {calc }}$.

molecular parameters are presented in Table 2. The correlation matrix is given in Table 3.

\section{DISCUSSION}

Observed and calculated [8] amplitudes of vibration are in satisfactory agreement. The bond length of $1.561 \AA$ is appreciably shorter than the $1.568 \pm 0.001 \AA$ mean $\mathrm{S}-\mathrm{F}$ bond length in $\mathrm{SF}_{5} \mathrm{Cl}$ consistent with expectations of the VSEPR theory [7]. In the most primitive VSEPR interpretation, it might appear that the axial $\mathrm{S}-\mathrm{F}$ bond length in $\mathrm{SF}_{5} \mathrm{Cl}$ should closely resemble that in $\mathrm{SF}_{6}$. Equatorial $\mathrm{S}-\mathrm{F}$ bonds in $\mathrm{SF}_{\mathrm{s}} \mathrm{Cl}$, however, would be expected to be lengthened, relative to those in $\mathbf{S F}_{6}$, by the effect of the adjacent, less electronegative ligand $\mathrm{Cl}$. This lengthening is, indeed, observed. It turns out, contrary to the zeroth-order guess, that the axial $\mathbf{S}-\mathbf{F}$ bond in $\mathbf{S F}_{5} \mathrm{Cl}$ is even longer. This additional lengthening has been interpreted as a "secondary relaxation effect" arising as a consequence of the "repulsion" of the equatorial fluorines by the chlorine $[1,9]$. As the $\mathrm{CISF}_{\mathrm{cq}}$ angle relaxes to its equilibrium angle in excess of $90^{\circ}$, an increasing 
TABLE 2

Derived molecular parameters and estimated errors ${ }^{\mathrm{a}}$ for $\mathbf{S F}_{6}$

\begin{tabular}{lll}
\hline Parameters & $r_{g}(\AA)$ & $l_{g}(\AA)$ \\
\hline S-F & $1.561 \pm 0.002$ & $0.044 \pm 0.001$ \\
F.- F cis & & $0.061 \pm 0.002$ \\
F.- F trans & & $0.056 \pm 0.006$
\end{tabular}

Index of resolution, nozzle to plate distance, sector $0.89\left(21 \mathrm{~cm}, r^{3}\right), 0.83\left(11 \mathrm{~cm}, r^{3}\right)$, $0.85\left(7 \mathrm{~cm}, r^{3}\right)$

a Estimated uncertainties represent $3 \sigma$ and include random and suspected systematic errors and our estimate of the effects of correlation between neighboring data points (with $\gamma=1.2 \AA$ ). Systematic standard errors are estimated to be 2 parts per ten thousand in wavelength measurement, 3 parts per ten thousand in nozzle to plate distance measurement, 2 parts per ten thousand in radial measurement in microphotometer scanning.

\section{TABLE 3}

Matrix of correlation coefficients for $\mathrm{SF}_{6}{ }^{a}$

\begin{tabular}{lccccc}
\hline & $r_{S F}$ & $l_{S F}$ & $l_{F F}$ cis & $l_{\text {FF }}$ trans & $R^{\mathrm{b}}$ \\
\hline$\sigma$ & 0.00032 & 0.00047 & 0.0021 & 0.00063 & 0.0079 \\
$r_{\text {SF }}$ & 100 & 5 & 4 & 1 & 6 \\
$l_{\text {SF }}$ & & 100 & 3 & 6 & 58 \\
$l_{\text {FF }}$ cis & & & 100 & 5 & 49 \\
$l_{\text {F }}$ trans & & & & 100 & 10 \\
$R$ & & & & & 100 \\
\hline
\end{tabular}

${ }^{a}$ Units for $\sigma$ are $\AA$ for distances and amplitudes. Matrix elements are given by $\rho_{i j}=\left(M_{x}^{w}\right)_{i j} /$ $\left[\left(M_{x}^{w}\right)_{i i}\left(M_{x}^{w}\right)_{j j}\right]^{1 / 2}$, where $M_{x}^{w}$ corresponds to the error matrix of Bartell and Anashkin [J. Mol. Struct., 17 (1973) 193] for Markovian noise. All entries, except $\sigma$ have been multiplied by 100 . bIndex of resolution.

stress is brought to bear on the axial fluorine. The present information is pleasingly consistent with this interpretation. Since the nonbonded distances in $\mathrm{SF}_{5} \mathrm{Cl}$ and $\mathrm{SF}_{6}$ are closely comparable to the sums of the nonbonded radii of tightly packed atoms as suggested by Bartell [10] and Glidewell et al. [11], a significant proportion of the intramolecular stress may be atom-atom in origin rather than bond-bond as hypothesized in the VSEPR theory.

\section{ACKNOWLEDGEMENTS}

This work was supported by a grant from the National Science Foundation. We thank the University of Michigan Computing Center for a generous allocation of computing time. 


\section{REFERENCES}

1 C. J. Marsden and L. S. Bartell, Inorg. Chem., 15 (1976) 3004.

2 J. P. Aldridge II, J. H. Birely, C. D. Cantrell III and D. C. Cartwright, in S. F. Jacobs, M. Sargent III, M. O. Scully and C. T. Walker (Eds.), Laser Photochemistry, Tunable Lasers, and Other Topics (Physics of Quantum Electronics, Vol. 4), Addison-Wesley, Reading, Mass., 1977.

3 D. M. Yost, C. C. Steffens and S. T. Gross, J. Chem. Phys., 2 (1934) 311 ; A. Eucken and $H$. Ahrens, Z. Phys. Chem. Abt. B, 26 (1934) 297; R. T. Lagemann and E. A. Jones, J. Chem. Phys., 19 (1951) 534; C. W. Gullikson, J. R. Nielsen and A. T. Stair Jr., J. Mol. Spectrose., 1 (1957) 151.

4 H. Braune and S. Knoke, Z. Phys. Chem. Abt. B, 21 (1933) 297.

5 L. O. Brockway and L. Pauling, Proc. Nat. Acad. Sci. U.S., 19 (1933) 68.

6 V. C. Ewing and L. E. Sutton, Trans. Faraday Soc., 59 (1963) 1241.

7 R. J. Gillespie and R. S. Nyholm, Q. Rev. Chem. Soc., 11 (1957) 389; R. J. Gillespie, Molecular Geometry, Van Nostrand-Reinhold, New York, 1972.

8 L. S. Bartell, F. B. Clippard and E. J. Jacob, Inorg. Chem., 15 (1976) 3009.

9 J. Brunvoll (unpublished) as cited by S. J. Cyvin, Molecular Vibrations and Mean Square Amplitudes, Universitetsforlaget, Oslo, 1968.

10 L. S. Bartell, J. Chem. Phys., 32 (1960) 832.

11 C. Slidewell, D. W. H. Rankin, A. G. Robiette and G. M. Sheldrick, J. Mol. Struct., o (1970) 231; C. Glidewell and A. G. Robiette, Chem. Phys. Lett., 28 (1974) 290; C. Glidewell, Inorg. Chim. Acta, 12 (1975) 219. 